\title{
HUBUNGAN KONSEP SETING FISIK DAN KONSEP PERILAKU DI AREA DEPAN GEDUNG REKTORAT Studi Kasus: Universitas Negeri Yogyakarta
}

\author{
Adimas Kristiadi \\ Staf Pengajar Program Studi Teknik Arsitektur, Fakultas Arsitektur dan Desain, \\ Universitas Kristen Duta Wacana \\ Jl. dr. Wahidin Sudirohusodo 5 - 25, Yogyakarta \\ Email: adimas.kristiadi@staff.ukdw.ac.id atau adimaskristiadi90@gmail.com
}

\begin{abstract}
Abstrak
Mahasiswa adalah "aktor" dalam universitas karena kegiatannya yang membutuhkan wadah, yaitu suatu lingkungan baik di dalam atau sekitar universitas. Menjadi menarik ketika mahasiswa berkegiatan di area sekitar gedung rektorat yang merupakan lingkungan bagi kegiatan rektor dan karyawan universitas, hal tersebut terjadi di area depan gedung rektorat Universitas Negeri Yogyakarta (UNY) yang memiliki kualitas ruang yang nyaman (fit). Ruang yang fit di area depan gedung rektorat UNY didasarkan dari persepsi (kognisi dan skemata) dan adaptasi mahasiswa UNY yang melihat adanya faktor-faktor kualitas (properti) pada lingkungan (seting fisik) dan mempengaruhi kegiatan (perilaku) mahasiswa UNY. Hubungan antara kegiatan (pola perilaku) mahasiswa UNY dengan tatanan lingkungan (seting fisik) yang spesifik area di depan gedung rektorat UNY dapat diartikan sebagai seting perilaku. Metode yang digunakan deduktif-kualitatif dengan paradigma rasionalistik. Data diperoleh dari observasi, pemetaan perilaku, wawancara, dan kuesioner, dianalisis secara induksi dan dibahas tersturktur. Temuan penelitian yaitu: 1) properti vertikal memberikan kenyamanan fisik dan kenyamanan sosial; 2) properti kedekatan jarak memberikan kenyamanan lingkungan; 3) properti distribusi pencahayaan buatan memberikan kenyamanan sosial; 4) properti yang menggambarkan situasi alami yang mendapatkan perlindungan memberikan kenyamanan fisik dan kenyamanan lingkungan.
\end{abstract}

Kata Kunci: seting perilaku, seting fisik, perilaku, komponen, properti

\section{Abstract \\ Title: The Relation of Physical Setting Concept and Behavior Concept in the Front of Rectorate Building, Case Study: Yogyakarta State University}

Students are the "actors" in the university because of their activities. Students need a certain space in the environment around the university. It becomes interesting when students do their activities around the building that is also the environment for rector and university employees, those happened at the area in front of Yogyakarta State University (UNY) rectorate building. There was a cozy quality (fit) space in there based on perception (cognition and schemata) and adaptation of $U N Y$ students for area of the UNY rectorate building. There were some quality factors (property) which is included as environment (physical setting) that affect the activity (behavior) of UNY students. The correlation between activity (behavior pattern) and specific environmental order (physical setting) interpreted as behavior setting. The method used is deductive-qualitative with rationalist paradigm. The data obtained were the result of observation, behavior mapping, interviews, questionnaires, with induction analyzed. The results are: 1) the vertical property provided physical comfort and social comfort; 2) the proximity property provided environmental comfort; 3) the artificial lighting distribution property provided social comfort; 4) the property of which describes the situation of natural protection provided physical comfort and environmental comfort.

Keywords: behavior setting, physical setting, behavior, component, property 


\section{Pendahuluan}

Mahasiswa adalah salah satu "aktor" dalam universitas karena kegiatannya. Kegiatan tersebut pastinya dilakukan dalam wadah kegiatan, yaitu lingkungan baik di dalam atau di sekitar universitas. Ada hubungan yang menarik dari kegiatan mahasiswa dengan wadah kegiatannya yang terjadi di lingkungan Universitas Negeri Yogyakarta (UNY), yaitu mahasiswa UNY melakukan kegiatan di area di depan gedung rektorat UNY yang sesungguhnya area gedung rektorat UNY dikhususkan sebagai wadah kegiatan bagi rektor dan karyawan UNY. Ada sebuah kualitas ruang yang nyaman (fit) pada area gedung rektorat UNY yang didasarkan dari persepsi (kognisi: apa yang dipahami dan dipelajari; skemata: pengalaman masa lampau tentang lingkungan yang sudah terekam dalam pikiran) dan adaptasi mahasiswa UNY terhadap area di depan gedung rektorat UNY. Ada faktor-faktor kualitas dari area di depan gedung rektorat UNY yang merupakan lingkungan (seting fisik) yang mempengaruhi kegiatan (perilaku) mahasiswa UNY. Hubungan antara kegiatan (pola perilaku) mahasiswa UNY dengan tatanan lingkungan (seting fisik) yang spesifik area di depan gedung rektorat UNY dapat diartikan sebagai seting perilaku (Laurens, 2004). Peneliti ingin memahami seting perilaku mahasiswa UNY yang terbentuk di area di depan gedung rektorat UNY. Maka muncul pertanyaan penelitian sebagai berikut:

1) Bagaimana bentuk seting perilaku oleh kegiatan mahasiswa UNY yang menggunakan area di depan gedung rektorat UNY?

2) Bagaimana karakteristik perilaku mahasiswa UNY dan karakteristik seting fisik area di depan gedung rektorat UNY sehingga terbentuk seting perilaku seperti yang terlihat?

Tujuannya adalah dapat merumuskan bentuk seting perilaku serta merumuskan karakteristik perilaku mahasiswa UNY dan karakteristik seting fisik area di depan gedung rektorat UNY, sehingga dapat menemukan kualitas dasar dari seting fisik yang sesuai khususnya bagi perilaku mahasiswa UNY di area di depan gedung rektorat UNY, ataupun bagi mahasiswa secara umum dalam suatu fasilitas tempat kegiatan mahasiswa di area universitas. Lokasi penelitian yaitu area di depan gedung rektorat UNY, Karangmalang, Jl. Colombo No. 1, Sleman, Yogyakarta, terbagi menjadi dua bagian yaitu area yang tertutupi atap dan area yang tidak tertutupi atap.

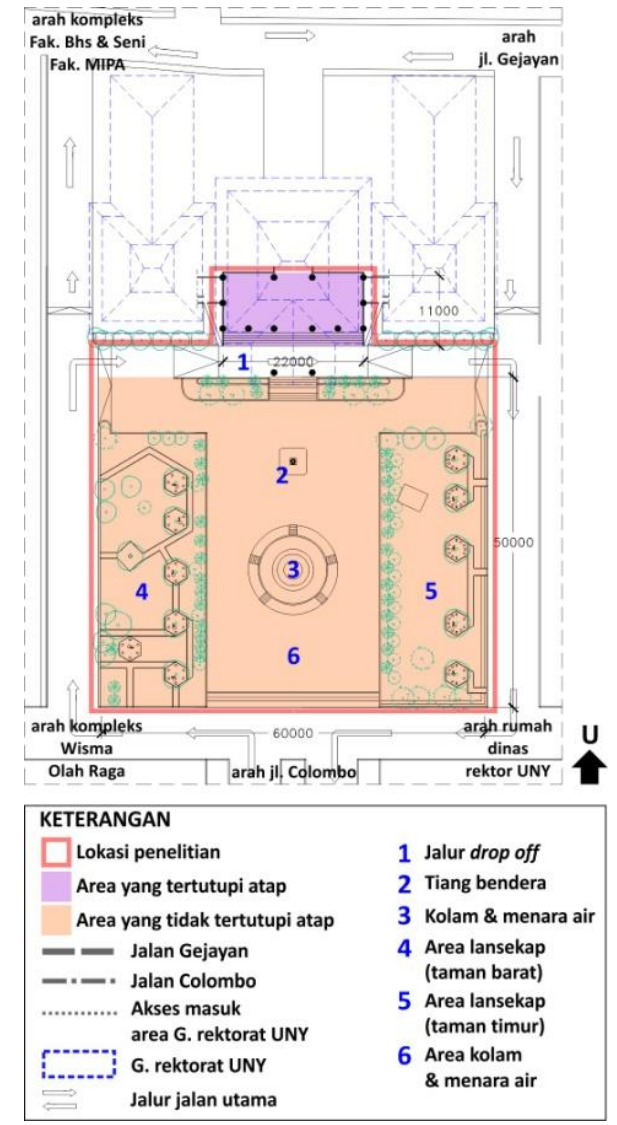

Gambar 1. Lokasi penelitian

Sumber: Dokumentasi Kristiadi, 2015 


\section{Kajian Teori}

Perilaku merupakan segala respon manusia terhadap stimulus dari luar (Notoatmodjo, 2003). Jika dihubungkan dengan arsitektur (ilmu tentang ruang), pendekatan perilaku menekankan pada keterkaitan yang dialektik (ada langkah berpikir secara teratur dan logis yang mendahuluinya) antara ruang dengan manusia yang memanfaatkan ruang tersebut. Manusia merupakan makhluk berpikir yang memiliki persepi (keputusan berpikir) dalam interaksinya dengan lingkungan (ruang kegiatan) (Moore, 1979). Persepsi adalah interpretasi suatu lingkungan oleh manusia yang interpretasi antara manusia yang satu dengan lainnya berbeda atau mirip tergantung dengan nalar serta pengalaman sosial, budaya, dan lingkungan fisik. Persepsi didahului oleh kognisi dimana manusia mendapatkan, menggambarkan, mengatur, menyerap, memahami informasi dan menggunakan pengetahuannya untuk memberi arti terhadap lingkungan. Dari berbagai kognisi yang telah dibentuk maka akan menghasilkan skemata dimana manusia menstrukturkan kembali rangkuman pengalaman terhadap lingkungan baik yang sudah atau sedang dialami. Kognisi, skemata, dan persepsi berlangsung secara simultan.

Perilaku manusia dalam lingkungan yang berdasarkan dari kognisi (apa yang dipahami) dan dari skemata (pengalaman masa lalu yang terekam dalam pikiran) menunjukkan adanya kemampuan manusia untuk melakukan perilaku adaptasi dalam kondisi lingkungan yang dihadapinya agar tercapai keseimbangan (kenyamanan) dengan lingkungan yang diinginkannya atau sesuai dengan tujuannya (goals). Adaptasi berarti perilaku yang muncul karena menanggapi stimulus yang ada pada lingkungan untuk memperoleh kenyamanan sesuai dengan yang diinginkan (fit). Adaptasi memiliki tiga model (Altman, 1980), yaitu adaptation by adjustment (merubah perilaku manusia agar sesuai dengan lingkungan); adaptation by reaction (merubah lingkungan agar sesuai dengan kondisi yang diinginkan); adaptation by withdrawl (lari keluar dari lingkungan). Sedangkan kenyamanan lingkungan (konsep fit \& misfit), yaitu indikasi dalam merasakan kesesuaian atau ketidaksesuaian suatu lingkungan (Alexander, 1964).

Lingkungan tempat manusia melakukan kegiatan disebut dengan seting (Rapoport, 1977). Seting memiliki makna lebih luas daripada istilah ruang yang bersifat spasial. Seting mecangkup tatanan lingkungan fisik, tatanan lingkungan sosial, lingkungan sekitar, manusia dengan kegiatannya (Haryadi dan Setiawan, 2010). Tatanan lingkungan fisik terdiri dari komponen dan properti (kualitas komponen) yaitu (Weisman, 1981): komponen fix (elemen yang pada dasarnya tetap seperti dinding, kolom, atap); komponen semi-fix (elemen yang agak tetap seperti street furniture, vegetasi, sirkulasi); komponen non-fix (elemen yang berhubungan dengan perilaku manusia yang selalu tidak tetap seperti posisi, postur, gerak tubuh). Tatanan lingkungan sosial dapat disebut dengan aturan atau norma yang melekat pada lingkungan. Tatanan lingkungan sekitar dapat disebut dengan lingkungan alami seperti suara, temperatur, cahaya matahari, dan hujan (Haryadi dan Setiawan, 2010). Adapun kualitas yang dirasakan manusia dalam seting dapat disebut atribut yang berjumlah 12 (Weisman, 1981): kenyamanan, 
sosialitas, visibilitas, aksesibilitas, rangsangan inderawi, aktivitas, kontrol, makna, legabilitas, adaptasi, privasi, dan kesesakan. Seluruh komponen dalam tatanan lingkungan memiliki kualitas atau properti.

Seting perilaku adalah kombinasi antara pola perilaku manusia dengan tatanan lingkungan (Laurens, 2004). Kombinasi tersebut yaitu adanya aktivitas yang berulang (a recurrent activity) sehingga menciptakan pola perilaku (standing pattern of behavior), terdapat tatanan lingkungan yang spesifik (circumjacent milieu), dan pola perilaku yang terjadi pada periode waktu tertentu (a specific time period). Dari kombinasi tersebut terbentuklah suatu synomorphy, kesesuaian antara pola perilaku dengan seting spesifik. Perilaku antar manusia juga saling terkait dan dapat mempengaruhi seting perilaku. Kaitan tersebut adalah privacy yaitu kemampuan seseorang untuk mengendalikan proses interaksi (Rapoport, 1977), personal space yaitu wilayah dengan batas maya tak terlihat yang melingkupi tubuh seseorang sehingga pengganggu tidak dapat memasukinya (Altman, 1975), territory yaitu ruang yang dibatasi oleh pelakunya dimana ruang tersebut digunakan, dipertahankan, dan dijaga secara eksklusif (Altman, 1975), crowding yaitu situasi ketika seseorang sudah tidak mampu mempertahankan ruang privatnya (Haryadi dan Setiawan, 2010).

Jadi, didapatkan landasan teori sebagai latar pengetahuan penelitian yaitu: Manusia hidup memiliki tujuan yang ingin dicapai (goals) dengan cara melakukan kegiatan (berperilaku) dalam lingkungan (seting) sehingga muncul bentuk seting perilaku, yaitu kombinasi antara konsep seting fisik dengan konsep perilaku yang dipengaruhi oleh persepsi manusia terhadap seting fisik, konsep fit \& misfit dari seting fisik, dan adaptasi manusia terhadap seting fisik hingga terjadi kesesuaian (synomorphy). Konsep seting fisik meliputi komponen fix, semi-fix, non-fix, serta lingkungan. Konsep perilaku meliputi privacy, personal space, territory, crowding. Peraturan atau kebijakan juga mempengaruhi seting perilaku.

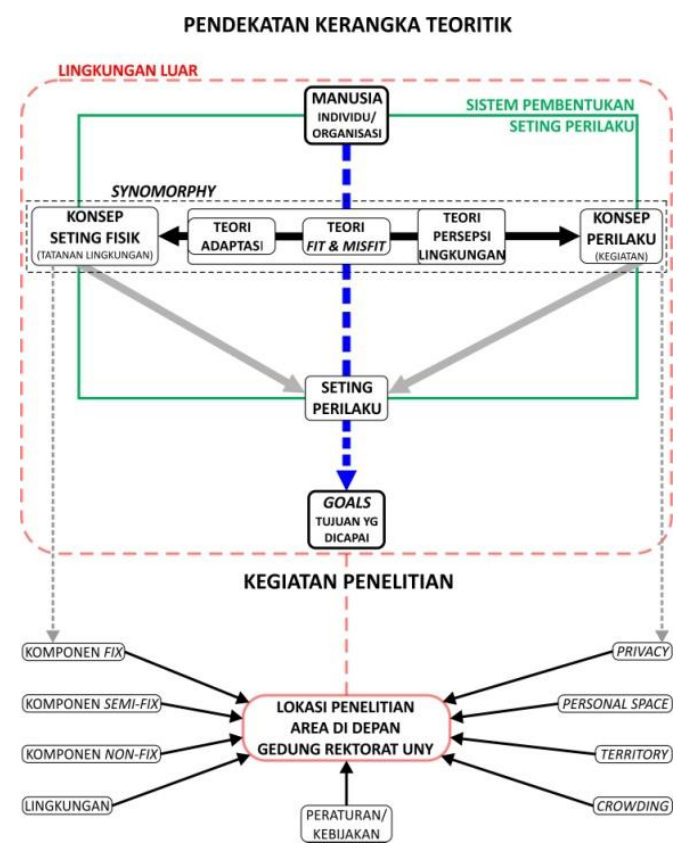

Gambar 2. Kerangka teori penelitian

Sumber: Olahan data Kristiadi, 2015

\section{Metode Penelitian}

Penelitian ini menggunakan metode deduktif-kualitatif dengan paradigma rasionalistik, melihat kebenaran bukan semata dari empiris tetapi juga dari argumentasi suatu bagian konstruksi berpikir. Data yang diperoleh adalah hasil observasi, pemetaan perilaku sebanyak 135 kali kepada 799 mahasiswa UNY (761 mahasiswa S1 UNY, 38 mahasiswa S2 UNY) dan hasil wawancara, serta kuesioner semantic differential dengan analisis 
faktor yang dilakukan kepada 150 mahasiswa UNY. Waktu penelitian disesuaikan dengan kegiatan mahasiswa UNY, setiap hari dari Senin-Minggu pada siang hari (10.0014.00) dan malam hari (16.00-21.00). Lokasi penelitian dirasa terlalu luas dan dibagi menjadi 4 antara lain: 1) area yang tertutupi atap; area yang tidak tertutupi atap dibagi menjadi tiga terdiri dari: 2) area lansekap taman barat; 3) area lansekap taman timur; 4) area kolam \& menara air. Data dianalisis secara induksi, digunakan untuk mengembangkan banyak fakta yang didapatkan di lapangan (Lincoln \& Guba, 1985) yaitu: 1) pengumpulan data awal; 2) klasifikasi data; 3) kategorisasi data; 4) pembentukan hipotesis.

\section{Hasil dan Pembahasan}

Identifikasi Konsep Seting Fisik dan Konsep Perilaku pada Lokasi Penelitian

Identifikasi yang dimaksud adalah proses mengumpulkan data seting fisik area di depan gedung rektorat UNY dan data perilaku mahasiswa UNY lalu mengklasifikasikannya sesuai dengan persamaan ciri-ciri yang ada. Identifikasi konsep seting fisik mengacu pada komponen fix, semi-fix, non-fix, serta lingkungan. Identifikasi konsep perilaku mengacu pada privacy, personal space, territory, crowding termasuk juga 12 atribut. Identifikasi konsep seting fisik didapatkan dengan observasi, sedangkan identifikasi konsep perilaku didapatkan dengan obervasi perilaku, wawancara, pemetaan perilaku, time budget, dan kuesioner. Proses identifikasi data ini dilakukan pada keempat bagian lokasi penelitian.
Kategorisasi Identifikasi Konsep Seting Fisik dan Konsep Perilaku

Pertama, kategorisasi dilakukan pada hasil identifikasi konsep perilaku yang diharapkan dapat menemukan pola perilaku yang terjadi secara manifesto (perwujudan perilaku tentang tujuan yang direncanakan dalam seting) dan laten (perilaku yang tersembunyi, terpendam namun berpotensi muncul agar kegiatan yang termanifestokan dapat berlangsung dengan kualitas yang diinginkan). Kemudian, pola perilaku manifesto dan laten dipahami secara mendalam agar menemukan karakteristik perilaku. Kedua, kategorisasi selanjutnya dilakukan pada hasil identifikasi konsep seting fisik dan dihubungkan dengan pola perilaku yang laten. Hubungan tersebut dipahami secara mendalam agar menemukan karakteristik seting fisik. Proses kategorisasi identifikasi konsep perilaku dan identifikasi konsep seting fisik ini dilakukan pada keempat bagian lokasi penelitian.

\section{Karakteristik Perilaku Mahasiwa UNY dan Karakteristik Seting Fisik Area di Depan Gedung Rektorat UNY}

Karakteristik perilaku mahasiswa dan karakteristik seting fisik yang ditemukan pada keempat bagian lokasi penelitian kemudian digabung menjadi satu kesatuan lokasi penelitian berdasarkan ciri-ciri atau sifat yang sama, mirip, atau dalam satu pengertian sehingga diperoleh karakteristik perilaku mahasiswa UNY dan karakteristik seting fisik area di depan gedung rektorat UNY. Karakteristik perilaku mahasiswa UNY berjumlah 11 buah dan karakteristik seting fisik area di depan gedung rektorat UNY berjumlah 9 buah, sebagai berikut: 
Karakteristik Perilaku Mahasiswa UNY

1) Posisi yang nyaman bagi tubuh saat berkegiatan yaitu bersila, duduk, dan bersandar.

2) Untuk menegaskan area kegiatan di dalam seting yang luas (horisontal), maka kegiatan dilakukan dekat dengan komponen fisik yang bersifat vertikal (tangga utara area kolam \& menara air, pot-pot tanaman, dinding kolam, list beton) di dalam seting.

3) Untuk meminimalisir gangguan dari orang lain dalam seting maka kegiatan dilakukan di tepi-tepi batas seting (tangga, dinding, kolom).

4) Untuk mendapatkan sumber listrik guna mendukung kegiatan dalam seting maka kegiatan dilakukan dekat dengan stop kontak.

5) Kemudahan bersirkulasi diwujudkan dengan parkir di dekat pusat kegiatan atau berkegiatan dengan jarak terdekat dari jalan utama.

6) Mempertegas batas dan penanda area kegiatan dilakukan dengan meletakkan benda-benda fisik (tas, jaket, tempat minum, laptop, buku, helm, serta barang yang mudah dibawa atau dipindah) di sekitar tubuh atau seting saat berkegiatan.

7) Untuk menyendiri atau intim dengan seseorang dan tidak mudah terlihat maka kegiatan dilakukan dekat dengan lampu taman yang memiliki cahaya remang dengan jangkauan cahaya yang sempit.

8) Untuk meminimalisir gangguan cuaca (panas matahari, air hujan, angin kencang) maka kegiatan dilakukan di dalam seting yang memiliki atap permanen.

9) Untuk mendapatkan suasana kesejukan udara alami maka kegiatan dilakukan di dalam seting yang berupa lansekap yang memiliki elemen vegetasi.
10) Menjauhi seting area kolam \& menara air pada siang hari karena digunakan sebagai area parkir mobil karyawan UNY.

11) Menjauhi seting area yang tertutupi atap saat fasilitas stop kontak (hanya tersedia 2 buah) seluruhnya terpakai.

Karakteristik Seting Fisik Area di Depan Gedung Rektorat UNY

1) Komponen fisik dengan sifat vertikal (punya ketinggian dan kedalaman) digunakan untuk kenyamanan tubuh (bersandar dan duduk).

2) Komponen fisik dengan sifat vertikal (yang dapat dengan jelas dilihat di antara seting yang bersifat horisontal) menjadi penanda pusatpusat kegiatan.

3) Stop kontak yang merupakan fasilitas sumber listrik menjadi penanda pusat-pusat kegiatan.

4) Area parkir dan jalur sirkulasi dapat berubah secara fleksibel agar dekat dengan pusat-pusat kegiatan.

5) Jalur sirkulasi terbentuk secara alami dengan mencari jarak terdekat dengan pusat-pusat kegiatan.

6) Benda-benda fisik (tas, jaket, tempat minum, laptop, buku, helm) yang mudah dibawa dan dipindahkan memperjelas secara visual batasbatas kegiatan.

7) Cahaya lampu taman yang remang dengan jangkauan cahaya yang sempit sebagai pembentuk batas ruang pribadi yang tidak mudah terlihat.

8) Atap yang permanen pada seting meminimalisir gangguan cuaca saat berkegiatan.

9) Vegetasi berfungsi sebagai peneduh alami namun tidak permanen dan memberikan suasana alami. 
Seting Perilaku Mahasiswa UNY di Area di Depan Gedung Rektorat UNY

Hubungan Karakteristik Perilaku dan Karakteristik Seting Fisik yang Pertama

Persepsi mahasiswa UNY tentang posisi tubuh yang nyaman saat berkegiatan adalah duduk dan bersandar (sesuai dengan karakter fisik) (Weisman, 1981). Tangga berundak dan area perkerasan yang memiliki elevasi serta dinding dan kolom pada seting dipandang mahasiswa UNY memiliki konteks dan bentuk yang fit untuk meletakkan pantat serta kaki dan menyandarkan punggung. Maka mahasiswa UNY melakukan adaptation by adjustment dengan melakukan kegiatan pada komponen fisik tersebut.

Persepsi mahasiswa UNY untuk menghindari keintiman, meminimalisir gangguan dari orang lain (reverse) (Holahan, 1982) dapat diwujudkan dengan mengambil jarak terjauh dengan orang lain di dalam seting. Jarak terjauh dalam seting adalah tepitepi batas seting yaitu tangga, dinding, dan kolom dan dipandang memiliki konteks dan bentuk yang fit untuk menghindari keintiman, meminimalisir gangguan dari orang lain. Maka mahasiswa UNY melakukan adaptation by adjustment dengan melakukan kegiatan dekat dengan komponen fisik tersebut.

Persepsi mahasiswa UNY di dalam area yang luas (horisontal) secara psikologis menjadikan area teritori menjadi kabur. Mahasiswa UNY membutuhkan suatu mekanisme untuk mengatur batas atau penandaan wilayah kegiatannya (Altman, 1975). Batas dan penandaan wilayah dapat diwujudkan dengan komponen fisik yang bersifat vertikal (agar mudah dilihat dalam area yang luas bersifat horisontal), yang ada pada tangga, list beton, pot-pot tanaman, dan dinding kolam dipandang memiliki konteks dan bentuk yang fit untuk batas dan penanda wilayah kegiatan. Maka mahasiswa UNY melakukan adaptation by adjustment dengan melakukan kegiatan dekat dengan komponen fisik tersebut.

Adapun batas penandaan teritori yang diwujudkan dengan komponen fisik yang bersifat vertikal (agar mudah dilihat dalam area yang luas bersifat horisontal) dapat dilakukan dengan meletakkan benda-benda fisik yang dibawa dan mudah dipindahkan di sekitar tubuh atau pada seting tertentu seperti laptop, tas, tempat minum, buku, sandal, helm, jaket. Benda-benda fisik tersebut dipandang memiliki konteks dan bentuk yang fit untuk batas dan penanda kegiatan. Maka mahasiswa UNY melakukan adaptation by adjustment dengan meletakkan benda-benda fisik tersebut di sekitar tubuh atau pada seting.

Pembahasan di atas menunjukkan mahasiswa UNY menginginkan suatu kenyamanan fisik (segala sesuatu yang berkenaan dengan sensasi tubuh yang dirasakan) dan kenyamanan sosial (segala sesuatu yang berkenaan dengan hubungan interpersonal) (Kolcaba, 2003). Kenyamanan fisik dan kenyamanan sosial didapat dengan berkegiatan dekat atau pada komponen fisik dalam seting seperti tangga, area perkerasan yang memiliki elevasi, dinding, kolom, list beton, pot-pot tanaman, dan benda-benda fisik yang dibawa seperti laptop, tas, tempat minum, buku, sandal, helm, jaket yang seluruhnya memiliki sifat vertikal (dominan berbentuk tegak lurus ke atas). Synomorphy yang terbentuk yaitu komponen fisik yang memiliki sifat vertikal di area di depan gedung 
rektorat UNY memberikan kenyamanan fisik (bagi organ tubuh kaki seperti duduk dan bagi organ tubuh punggung seperti bersandar) dan kenyamanan sosial (untuk menegaskan dan penanda batas-batas area kegiatan) bagi mahasiswa UNY saat melakukan kegiatan.

Hubungan Karakteristik Perilaku dan Karakteristik Seting Fisik yang Kedua Persepsi mahasiswa UNY membutuhkan alat-alat eletronik seperti laptop untuk mendukung kegiatannya, khususnya berhubungan dengan kegiataan kuliah. Adapun pada seting disediakan fasilitas wi-fi. Untuk itu mahasiswa UNY membutuhkan sumber listrik untuk mendukung kinerja alat-alat elektroniknya yang bersinergi dengan akses internet (wi-fi). Adanya fasilitas stop kontak sebagai sumber listrik yang berjumlah 13 pada seting dipandang memiliki konteks yang fit untuk mendukung kinerja alat elektronik. Maka mahasiswa UNY melakukan adaptation by adjustment dengan melakukan kegiatan dekat dengan komponen fisik tersebut.

Persepsi mahasiswa UNY mencari kemudahan dalam bersirkulasi, dekat dengan area parkir dan jalan utama (aksesibilitas) (Weisman, 1981). Aksesibilitas didapatkan dengan cara pencapaian melalui pandangan atau jarak tempuh yang secara langsung (tidak berbelok, tersamar, memutar) (Ching, 1996). Area parkir pada malam hari dapat muncul secara fleksibel untuk lebih dekat dengan pusat-pusat kegiatan. Hal tersebut dipandang memiliki konteks yang fit bagi pencapaian secara langsung. Mahasiswa UNY melakukan adaptation by reaction dengan mengubah area parkir pada malam hari. Adapun area pada seting merupakan ruang terbuka yang tidak dibatasi oleh dinding-dinding masif, sehingga sirkulasi mahasiswa UNY dapat terjadi secara fleksibel untuk langsung menuju pusat-pusat kegiatan. Hal tersebut dipandang memiliki konteks yang fit bagi pencapaian secara langsung. Mahasiswa UNY melakukan adaptation by adjustment dengan melakukan sirkulasi langsung menuju pusat-pusat area kegiatan untuk mendapatkan jarak terpendek menuju pusat-pusat kegiatan.

Pembahasan di atas menunjukkan mahasiswa UNY menginginkan suatu kenyamanan lingkungan (segala sesuatu yang berkenaan dengan kondisi dan pengaruhnya dari dalam atau dari luar suatu lingkungan kepada manusia yang juga berada dalam lingkungan tersebut) (Kolcaba, 2003). Kenyamanan lingkungan didapat dengan berkegiatan dekat atau pada komponen fisik dalam seting seperti fasilitas stop kontak yang dapat mendukung kegiatan mahasiswa UNY. Kenyamanan lingkungan juga berupa kedekatan jarak komponen fisik area parkir dan sirkulasi terhadap pusatpusat kegiatan mahasiswa UNY. Synomorphy yang terbentuk yaitu komponen fisik yang memiliki sifat kedekatan jarak di area di depan gedung rektorat UNY memberikan kenyamanan lingkungan (kedekatan jarak terhadap fasilitas stop kontak, area parkir, dan sirkulasi terhadap pusat-pusat area kegiatan) bagi mahasiswa UNY saat melakukan kegiatan.

Hubungan Karakteristik Perilaku dan Karakteristik Seting Fisik yang Ketiga Persepsi mahasiswa UNY untuk menyendiri atau intim dengan seseorang dan tidak mudah terlihat oleh orang lain (solitude dan intimacy) (Holahan, 1982) dapat diwujudkan dengan mencari area yang pribadi di 
dalam seting. Lampu taman area lansekap pada malam hari memberikan cahaya yang remang atau baur (diffuse) dengan jangkauan cahaya yang sempit (pencahayaan lokal atau setempat). Hal tersebut dipandang memiliki konteks dan bentuk yang fit sebagai ruang dengan kesan pribadi yang terbentuk dari cahaya. Maka mahasiswa UNY melakukan adaptation by adjustment dengan melakukan kegiatan pada komponen fisik tersebut.

Pembahasan di atas menunjukkan mahasiswa UNY menginginkan suatu kenyamanan sosial (segala sesuatu yang berkenaan dengan hubungan interpersonal) (Kolcaba, 2003). Kenyamanan sosial didapat dengan berkegiatan dekat atau di bawah komponen fisik dalam seting yang berupa lampu taman di area lansekap. Sifat cahaya lampu taman yang remang dengan fungsinya yang berupa pencahayaan setempat (menerangi area tertentu dengan jangkauan cahaya yang sempit) dapat membentuk suatu batasbatas ruang yang terkesan pribadi dan intim pada malam hari. Sifat dan fungsi dari lampu taman tersebut adalah inti dari konsep distribusi pencahayaan buatan (Frick, 2008). Synomorphy yang terbentuk yaitu komponen fisik yang berkaitan dengan pendistribusian pencahayaan buatan di area di depan gedung rektorat UNY memberikan kenyamanan sosial (lampu taman dengan cahaya remang dan jangkauan cahaya yang sempit memberikan kesan ruang pribadi dan intim) bagi mahasiswa UNY saat melakukan kegiatan.

Hubungan Karakteristik Perilaku dan Karakteristik Seting Fisik yang Keempat

Persepsi mahasiswa UNY saat melakukan kegiatan dipengaruhi oleh kualitas dan intensitas perangsang yang dirasakan oleh panca indera, atau juga disebut rangsangan inderawi (Weisman, 1981). Perangsang tersebut berupa panas cahaya matahari, air hujan, angin, dan faktor internal (selera atau kebiasaan pribadi).

Ada mahasiswa UNY berdasarkan rangsangan inderawi yang diterima memilih untuk berkegiatan di area yang terbuka dekat dengan vegetasi dan mendapatkan suasana alam (menerima panas cahaya matahari atau hembusan angin), yaitu di area yang tidak tertutupi atap area lansekap. Ada juga mahasiswa UNY berdasarkan rangsangan inderawi memilih untuk berkegiatan di area yang memiliki atap permanen dan mendapatkan suasana perlindungan (menolak panas cahaya matahari, air hujan, atau angin yang kencang), yaitu di area yang tertutupi atap. Area yang tidak tertutupi atap area lansekap dan area yang tertutupi atap dipandang memiliki konteks yang fit bagi rangsangan inderawi.

Kedua area tersebut tidak dapat dipisahkan, karena di saat area yang tidak tertutupi atap area lansekap terlalu terik, ada hujan lebat, dan angin kencang, mahasiswa UNY melakukan kegiatan di area yang tertutupi atap (melakukan adaptation by withdrawl menjauhi area yang tidak tertutupi atap area lansekap dan melakukan adaptation by adjustment melakukan kegiatan di area yang tertutupi atap). Begitupun sebaliknya, jika area yang tertutupi atap terlalu gerah tidak ada angin yang berhembus masuk, mahasiswa UNY melakukan kegiatan di area yang tidak tertutupi atap area lansekap (melakukan adaptation by withdrawl menjauhi area yang tertutupi atap dan melakukan adaptation by adjustment melakukan kegiatan di area yang tidak tertutupi atap area lansekap). 
Pembahasan di atas menunjukkan mahasiswa UNY menginginkan suatu kenyamanan fisik (segala sesuatu yang berkenaan dengan sensasi tubuh yang dirasakan) dan kenyamanan lingkungan (segala sesuatu yang berkenaan dengan kondisi dan pengaruhnya dari dalam atau dari luar suatu lingkungan kepada manusia yang juga berada dalam lingkungan tersebut) (Kolcaba, 2003). Kenyamanan fisik dan kenyamanan lingkungan didapat dengan berkegiatan dalam seting yang memiliki elemen vegetasi (pengatap, pedinding, pelantai) sehingga memberikan suasana alam yang sejuk dan kaya oksigen yaitu di area yang tidak tertutupi atap lansekap taman barat dan taman timur, serta berkegiatan dalam seting yang memiliki atap permanen yang dapat memberikan suasana perlindungan terhadap gangguan cuaca sehingga dapat terhindar dari panas matahari, air hujan, dan angin kencang yaitu di area yang tertutupi atap. Synomorphy yang terbentuk yaitu komponen fisik yang menggambarkan situasi alami yang mendapatkan perlindungan di area di depan gedung rektorat UNY memberikan kenyamanan fisik serta kenyamanan lingkungan yaitu mendapatkan suasana alami, sejuk, kaya oksigen, dan mendapatkan suasana perlindungan dari gangguan cuaca bagi mahasiswa UNY saat melakukan kegiatan.

Synomorphy atau keseuaian yang terbentuk dari keempat hubungan antara karakteristik perilaku dengan karakteristik seting fisik terhadap tujuan (goals) yang ingin dicapai mahasiswa UNY yang melakukan kegiatan di area di depan gedung rektorat UNY, menjelaskan bahwa pola perilaku mahasiswa UNY yang tercipta dipengaruhi oleh kualitas (properti) dari komponen fisik pada seting area di depan gedung rektorat UNY yang memiliki sifat vertikal, memiliki sifat kedekatan jarak, memiliki sifat distribusi pencahayaan buatan, dan memiliki sifat yang menggambarkan situasi alami yang mendapatkan perlindungan.

\section{Kesimpulan}

Kualitas atau properti dari komponen fisik area di depan gedung rektorat UNY (seting fisik) yang mempengaruhi pola perilaku mahasiswa UNY saat melakukan kegiatan agar sesuai dengan tujuan yang dicapai (goals) sebagai berikut:

1) Properti vertikal memberikan kenyamanan fisik (bagi organ tubuh kaki seperti duduk dan bagi organ tubuh punggung seperti bersandar) dan kenyamanan sosial (untuk menegaskan dan penanda batasbatas area kegiatan).

2) Properti kedekatan jarak memberikan kenyamanan lingkungan (kedekatan jarak terhadap fasilitas stop kontak, area parkir, dan sirkulasi terhadap pusatpusat area kegiatan).

3) Properti distribusi pencahayaan buatan memberikan kenyamanan sosial (lampu taman dengan cahaya remang dan jangkauan cahaya yang sempit memberikan kesan ruang pribadi dan intim).

4) Properti yang menggambarkan situasi alami yang mendapatkan perlindungan memberikan kenyamanan fisik dan kenyamanan lingkungan (mendapatkan suasana alami, sejuk, kaya oksigen, dan mendapatkan suasana perlindungan dari gangguan cuaca). 


\section{Daftar Pustaka}

Alexander, C. (1964). Notes on the synthesis of form. London: Harvard University Press.

Altman, I. (1975). The environment and social behavior: Privacy, personal space, territory, crowding. California: Brooks/Cole Publishing Company.

Ching, F. D. (1996). Arsitektur: Form, space, and order. New York: Van Nostrand Reinhold.

Frick. H. (2006). Ilmu fisika bangunan. Yogyakarta: Kanisius.

Haryadi; Setiawan, B. (2010). Arsitektur, lingkungan dan perilaku: Pengantar ke teori, metodologi dan qplikasi. Yogyakarta: Gadjah Mada University Press.

Holahan, C. J. (1982). Environmental psychology. New York: Random House.

Kolcaba, K. (2003). Comfort theory and practice: A vision for holistic health care and research. New York: Springer Publishing Company.

Laurens, J. M. (2004). Arsitektur dan perilaku manusia. Jakarta: PT Grasindo.

Lincoln, Y.S. \& Guba, E.G. (1985). Naturalistic inquiry. Beverly Hills, CA: Sage Publications Inc.

Moore, G. T. (1979). Environment behavior studies. New York: Mc Graw.

Notoatmodjo, S (2003). Pendidikan dan perilaku kesehatan. Jakarta: Rineka Cipta.

Rapoport, A. (1977). Human aspect of urban form. Oxford: Pergamon Press.

Weisman, G. (1981). Modelling environment behavior system:
A brief note. Journal of ManEnvironment Relations, 32-41. 